\title{
Effect of nanofillers on the properties of a state of the art epoxy gelcoat
}

\author{
P. Karapappas, P. Tsotra*, K. Scobbie \\ Huntsman Advanced Materials, Klybeckstrasse 200, Basel 4057, Switzerland
}

Received 29 July 2010; accepted in revised form 2 November 2010

\begin{abstract}
In this work, the effect of the inclusion of electrically conductive and non-conductive nanofillers in a state of the art epoxy gelcoat was studied. The conductive fillers used were multi-wall carbon nanotubes and exfoliated nanographite. The non-conductive ones were nanoclay and nano-titanium dioxide. The content of the nanofillers was $0.65 \%$ per weight and their inclusion took place using high shear mixing devices. The conductive fillers showed an increase in tensile and fracture properties, as well as in the thermal properties whereas the non-conductive fillers did not show any improvement on the fracture properties. The glass transition temperature was practically unaffected by the presence of the nanofillers while conversly, the coefficient of thermal expansion was decreased for all the nanofillers for temperatures above the glass transition temperature. Finally, weatherometer tests showed that the nanofillers contribute into less weight losses in comparison with the reference epoxy gelcoat.
\end{abstract}

Keywords: nanocomposites, nanofillers, gelcoats, weatherometer, mechanical properties

\section{Introduction}

There have been numerous studies that have demonstrated that, the use of conductive nanofillers like carbon nanotubes (CNTs), carbon nanofibres (CNFs) or nanographite can improve the mechanical properties of epoxy resins and their composites [1-5]. Also the electrical conductivity of polymers containing organic nanofillers can be further improved [6-10] since only a small fraction of nanotubes or nanographite is needed to form the percolation conductive network. The optimal dispersion of the nanofillers in the resin is a key factor for achieving the aforementioned properties. Moreover it has been established that, the CNTs can be used as sensors monitoring strain, applied loading, or even sense damage induced, etc. [11-14]. The thermal stability of polymers has also been enhanced with the inclusion of nanographite because of the 'barrier effect' which is strongly related to its shape and structure [15-16]. However the effect of the above mentioned fillers is not always the same on the glass transition temperature and is a phenomenon depending on various factors like the morphology and structure of the nanofillers, its chemical treatment, purity, functionalisation, etc [17]. Also, some of the more recent studies, used nanoclays for the reinforcement of carbon fabrics achieving important mechanical enhancements along with flame retardant abilities, i.e. reduce the peak heat release rate [18-23]. Titanium dioxide has also been used as a thermal barrier on composite application increasing the oxidation and degradation temperature of carbon fibres etc. Treating $\mathrm{TiO}_{2}$ with amino-silane coupling has increased the impact and tensile properties of polystyrene. Finally, the pyrolysis behaviour of PVA composites has been enhanced with the addition of nano- $\mathrm{TiO}_{2}$ [24-26]. Nevertheless, no research has been done so far on 
the effect of nanofillers on the properties of gelcoats. The current work focuses on how the properties of a state of the art epoxy gelcoat, can be enhanced with the addition of different nanofillers. A gelcoat is a material used to provide a high quality finish on the visible surface of a fibre-reinforced composite material. The most common gelcoats are based on epoxy or unsaturated polyester resin chemistry. Gelcoats are modified resins which are applied to moulds in the liquid state. They are cured to form crosslinked polymers and are subsequently backed up with composite polymer matrices, often mixtures of polyester resin and fibreglass or epoxy resin with glass, kevlar and/or carbon fibres. The manufactured component, when sufficiently cured and removed from the mould, presents the gelcoated surface. This is usually pigmented to provide a coloured, glossy surface which improves the aesthetic appearance of the component. Gelcoats are designed to be durable, providing resistance to ultraviolet degradation and hydrolysis. Specialised gelcoats can be used to manufacture the moulds which in turn are used to manufacture components. These require very high levels of durability to overcome the mechanical and thermal stresses encountered during the curing and demoulding processes. In the current work an effort was made to enhance the mechanical and thermal properties of the RenGel $^{\text {TM }} 5200$ gelcoat of Huntsman Advanced Materials $\mathrm{GmbH}$, Switzerland with the use of nanofillers. Fillers in any size have for many years had a high significance in the plastics industry. Nanofillers are basically understood to be additives in solid form where on dimension is in nanoscale and, differ from the polymer matrix in terms of their composition and structure. They generally comprise inorganic materials or organic materials. Inactive fillers or extenders raise the quantity and lower the prices, whereas active fillers bring about targeted improvements in certain mechanical or physical properties. The activity of active fillers may have a variety of causes, such as the formation of a chemical bond or filling of a certain volume and disruption of the conformational position of a polymer matrix, and also the immobilization of adjacent molecule groups and possible orientation of the polymer material.

\section{Experimental}

As reference material the RenGel ${ }^{\mathrm{TM}}$ SW 5200 epoxy gelcoat of Huntsman Advanced Materials $\mathrm{GmbH}$, Basel, Switzerland was used and was cured with Ren ${ }^{\circledR}$ HY 5212 Fast. The formulation of the gelcoat is based on Araldite ${ }^{\circledR}$ MY 0510, a trifunctional glycidylamine epoxy resin. The nanofillers that they were used to produce four different nanoenhanced gelcoats were the following: (i) MWCNTs Baytubes ${ }^{\circledR}$ C150P by Bayer ${ }^{\mathrm{TM}}$, Monheim, Germany with $95 \%$ purity, diameter between $13-$ $16 \mathrm{~nm}$, length $>1 \mu \mathrm{m}$ and, density $1.4-1.6 \mathrm{~g} / \mathrm{cm}^{3}$, (ii) the exfoliated nanographite platelets were by XG Sciences, Michigan, USA with trade name $\mathrm{xGnP}^{\circledR}$ Exfoliated Graphite Nanoplatelets. The platelets had $97 \%$ purity, thickness $5-10 \mathrm{~nm}$ and, density $1.9-2.2 \mathrm{~g} / \mathrm{cm}^{3}$, (iii) Cloisite ${ }^{\circledR} 30 \mathrm{~B}$ by Rockwood Additives, Austin, USA was chosen as the nanoclay filler. This particular montmorillonite clay filler has purity over $98 \%$, length between $2-13 \mu \mathrm{m}$, thickness in nano and, density $1.98 \mathrm{~g} / \mathrm{cm}^{3}$ and finally, (iv) nano-titanium dioxide in rutile form and $99 \%$ pure was used by MK Nano, Ontario, Canada with diameter of $50 \mathrm{~nm}$ and density of $4.23 \mathrm{~g} / \mathrm{cm}^{3}$. All the nanofillers were used in 'as received' form i.e. no surface modification or functionalisation took place.

The way that the nanofillers were introduced into the gelcoat was via their inclusion in the plain resin itself, forming thus a masterbatch. Then, the produced masterbatch was used as part of the formulation of the gelcoat. The dispersion of the nanofillers at $2 \%$ p.wt into the epoxy resin took place by using a high shear device. High shear devices include mixers, dissolvers, 3 roll-mills, etc and introduce high shear forces via rotating parts and sometimes turbulent flow, so as to break the agglomerates of the nanofillers and distribute the fillers uniformly in the resin.

In this work, for the inclusion of all the nanofillers a 3 roll-mill of ' $\mathrm{S}$ ' series by Exakt ${ }^{\circledR}$, Norderstedt, Germany was used. A three roll mill (also known as calender) is a machine tool that uses the shear force created by three horizontally positioned rolls rotating at opposite directions and different speeds relative to each other to mix, refine, disperse, or homog- 
enize viscous materials fed into it. The three adjacent rolls of a three roll mill rotate at progressively higher speeds. This milling cycle can be repeated several times to maximize dispersion. The gaps between the rolls can be mechanically or hydraulically adjusted and maintained. Typically, the gap distance is far greater than the particle size. In some operations, they are gradually decreased to achieve the desired level of dispersion. Also in the most advanced versions the rolls can be set so as to produce constant shear forces and they can also be heated or cooled independently so as to adjust the mixture's viscosity accordingly. The mixture of resin with the nanofillers was passed twice from the 3 roll-mill with the gap between the rolls to be set at 5 microns and the tip speed was set at $1.25 \mathrm{~m} / \mathrm{sec}$, in the second pass the gap was reduced at $2 \mu \mathrm{m}$ and the tip speed further increased at around $1.69 \mathrm{~m} / \mathrm{sec}$. At this point, it must be noted that the gap of $2 \mu \mathrm{m}$ was set manually while preparing the masterbatch. With the Exakt ${ }^{\mathbb{B}} 120 \mathrm{~S}$ used there is no way to control and maintain the gap constant throughout the mixing operation. For the preparation of the gelcoat a planetary mixer was used by EM, Italy. Contrary to conventional planetary mixers, the two blade configurations sweep the wall of the can clockwise and rotate in opposite directions at about three times the speed of travel. The shear blades displace the material from the walls of the can and by their overlapping action the center carry the particles towards the agitator shafts, therefore producing a large field of shear forces. By this means even highly viscous and cohesive material can be efficiently mixed. The masterbatch was introduced to the mixer and then the other fillers were added, one at a time. The duration of the mixing process was around 5 hours, the discs employed were impellers of $70 \mathrm{~mm}$ diameter with rotational speed around $200 \mathrm{rpm}$ and, the temperature was set at $80^{\circ} \mathrm{C}$. The mixing ratio of the gelcoat with the liquid hardener was 100:22 per weight and the curing schedule was the following: 24 hours room temperature +12 hours at $40^{\circ} \mathrm{C}+2$ hours at $80^{\circ} \mathrm{C}+2$ hours at $100^{\circ} \mathrm{C}+$ 2 hours at $120^{\circ} \mathrm{C}+2$ hours at $140^{\circ} \mathrm{C}+2$ hours at $160^{\circ} \mathrm{C}+2$ hours at $180^{\circ} \mathrm{C}+12$ hours at $200^{\circ} \mathrm{C}$ and slowly cooled down to room temperature. The resulting final mixture was cast in closed metallic moulds of different thicknesses so as to produce specimens for various tests.
In order to investigate and evaluate the effect of the nanofillers on the properties of the epoxy gelcoat several tests were performed. These tests include viscosity measurements at room temperature using a Brookfield rheometer by Brookfield, Boston, USA and the ASTM D2393 standard. The tensile coupons were prepared according ISO 527, the fracture coupons according to ISO 13586 and the torsion DMA according to ISO 6721. Moreover, the DC electrical volume conductivity measurements perfromed by a digital Keithley Electrometer 2000 by Keithley Instruments Inc, Cleveland, USA according to the IEC 60093 standard and, the thermal conductivity was measured by the C-Therm $\mathrm{TCi}$, instrument of Setaram, Caluire, France. The coefficient of linear thermal expansion was measured by the means of a TMA by Mettler Toledo, Zurich, Switzerland and according to the ISO standard 11359-2. Finally the weatherometer test took place by following the SAE J1885 standard for 300 hours using a Ci3000+ Xenon Weather-Ometer ${ }^{\circledR}$ by Atlas, Chicago, USA.

\section{Results and discussion}

The first chart (Figure 1) is a comparison of the rheological properties of the gelcoats with the different nanofillers against the reference gelcoat at room temperature. The volume fraction for the nanofillers was approximately $0.43,0.31,0.33$ and $0.15 \%$ for the CNTs, the exfoliated nanonographite, the nanoclay and the titanium dioxide respectively. It can be seen that for shear rates of around $10 \mathrm{~Hz}$ and above, all the gelcoats have in practice the same viscosity. However at lower shear rates the high aspect ratio of the CNTs and the layered structure of the nanoclay increased the viscosity of the refer-

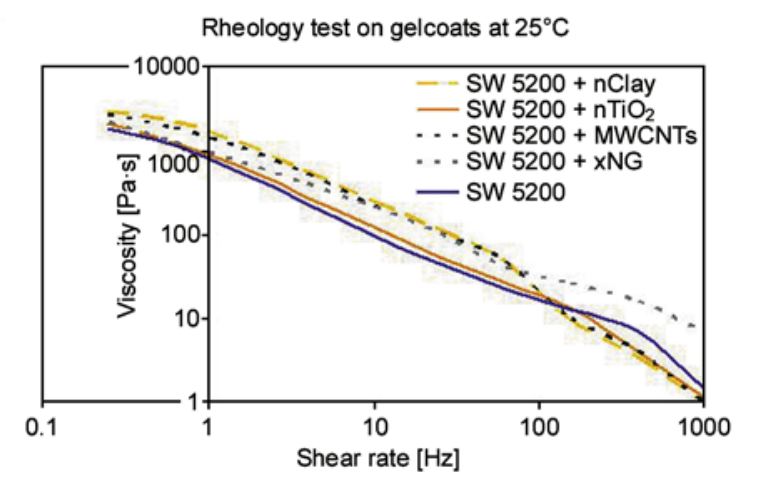

Figure 1. Log-log plot of the rheology properties of the epoxy gelcoats 
ence gelcoat around $30-40 \%$. The above effect is strongly connected with the structure, morphology, density, volume fraction and the aspect ratio of the fillers. Therefore the carbon nanotubes by having a larger aspect ratio (thinner and longer) and higher volume fraction than the exfoliated nanographite have a bigger impact on the resin's viscosity. Moreover, the nanoclay layers have a high aspect ratio and each one is approximately $1 \mathrm{~nm}$ thick, with their diameter varying from $30 \mathrm{~nm}$ to several microns or larger having thus a bigger impact on the resin's viscosity than the titanium dioxide. Titanium dioxide has also lower volume fraction than the nanoclay used in this study. Besides, the reference gelcoat and the nano-doped ones are thixotropic and therefore no re-agglomeration on segregation was observed after storing them at room temperature for more than 90 days. The high polarity of the matrix is responsible for the thixotropy of the resulting gelcoats.

At this point it should be noted that given that the reference epoxy gelcoat is a commercially availiable system, the SEM pictures taken to evaluate the dispersion of the nanofillers cannot be disclosed since they could also reveal the type of the other microfillers used for its formulation. The SEM micrographs revealed that all nanofillers had a good dispersion and that a quite homogeneous mixture was manufactured. By stating 'good dispersion' the authors suggest that some small agglomerations were present but all the produced mixtures were directly comparable.

In the following Table 1 the results summary from the tensile tests are given, while Figure 2 shows representative stress-strain curves for the epoxy gelcoats. The beneficiary effect of all the nanofillers on the tensile properties is obvious. For all the cases the Elastic modulus, along with the maximum stress and strain at failure were significantly increased. The increase of the maximum stress values was in the range of $35-65 \%$ and for the maximum strain at failure was between $26-97 \%$. The

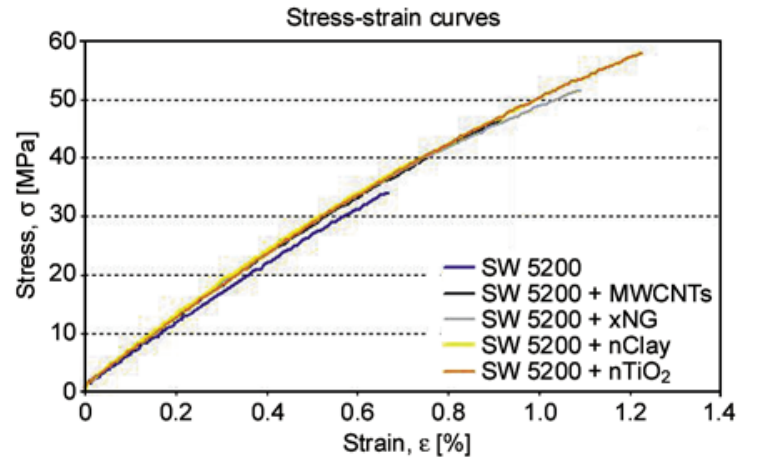

Figure 2. Stress-strain curves of the epoxy gelocoats

high aspect ratio of the CNTs, the high surface area (high interfacial area between nanofiller and polymer) and their excellent mechanical properties: elastic modulus of around $0.8 \mathrm{TPa}$, tensile strength of around $150 \mathrm{GPa}$ and elongation at break larger than $10 \%$, contributed to the increase of the tensile properties of the epoxy gelcoats [27-30]. While the layered exfoliated structure and the platelet shape of the nanographite is responsible for the enhanced tensile properties [31-34]. The reinforcing mechanisms of ceramic fillers like the titanium dioxide and the montmorillonite clay that were used in the present study have been attributed to their large surface area and surface reactivity of the inorganic phase, the corresponding restricted mobility of the polymer chains and to the increase in the effective particle volume fraction in the nanocomposite [35-37].

The fracture properties of the gelcoats can be seen in Figure 3. Once again the positive effect of the CNTs and the exfoliated nanographite is demonstrated. However in the contrary with the tensile properties, the ceramic fillers bring minor or no improvement at all. Specifically, in the case of the nanoclay, the fracture properties have decreased with respect to the reference system around 8.5\%. The differences on the properties for the organic and inorganic fillers are assigned to the dissimilar aspect ratios. A lot of researchers have concluded that the reinforcing mechanisms of the clays are

Table 1. Tensile properties of the nanomodified gelcoats versus the reference gelcoat

\begin{tabular}{|c|c|c|c|c|c|c|}
\hline \multirow{2}{*}{ Gelcoat reference } & \multicolumn{2}{|c|}{$\mathbf{E}$} & \multicolumn{2}{|c|}{$\sigma_{\max }$} & \multicolumn{2}{|c|}{$\varepsilon$} \\
\hline & [GPa] & st.dev & [MPa] & st.dev & {$[\%]$} & st.dev \\
\hline Rengel SW 5200 & 5.299 & 0.024 & 34.98 & 2.85 & 0.670 & 0.025 \\
\hline Rengel SW 5200 + MWCNTs & 5.654 & 0.039 & 47.68 & 5.86 & 0.850 & 0.041 \\
\hline Rengel SW $5200+$ xnGraphite & 5.823 & 0.064 & 54.00 & 3.42 & 1.160 & 0.026 \\
\hline Rengel SW $5200+$ nClay & 5.819 & 0.066 & 48.42 & 5.26 & 0.970 & 0.018 \\
\hline Rengel SW $5200+\mathrm{nTiO}_{2}$ & 5.604 & 0.079 & 57.84 & 2.21 & 1.320 & 0.023 \\
\hline
\end{tabular}




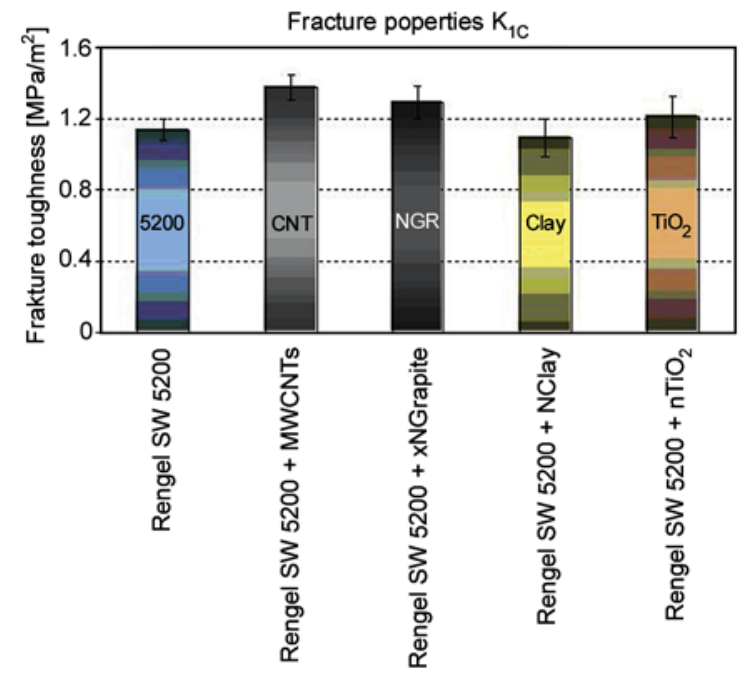

Figure 3. Fracture properties of the nanomodified gelcoats versus the reference gelcoat

crack arrest, crack pinning, crack bifurcation and shear deformation [38-40]. The inorganic fillers i.e. the nanoclay and the titanium dioxide have aspect ratios between 10-100. On the other hand the CNTs and the nanographite have aspect ratios greater than 500 (sometimes even 1000) and elongation at break greater than $10 \%$. Their reinforcing mechanisms have been revised in the literature and claim that the significantly large aspect ratio of the fillers which allows them to act as nano-bridges between the notch edges. Extra energy is needed in order to pull them out from the matrix or break them and then initiate the crack propagation. This extra energy is then translated into improved fracture toughness properties $[1,4,14,27-30]$. When directly comparing the two inorganic nanofillers, it is clear that the titanium dioxide particles are nanosized and therefore they can be more effective on reinforcing the fracture properties of the polymer than the clays which are nanosized only through thickness. Also, by comparing the tensile data of the previous section is clear that the inclusion of the nanoclay made the epoxy gelcoat more brittle than the gelcoat with titanium dioxide. A more brittle material is less fracture tolerant and hence the difference on the

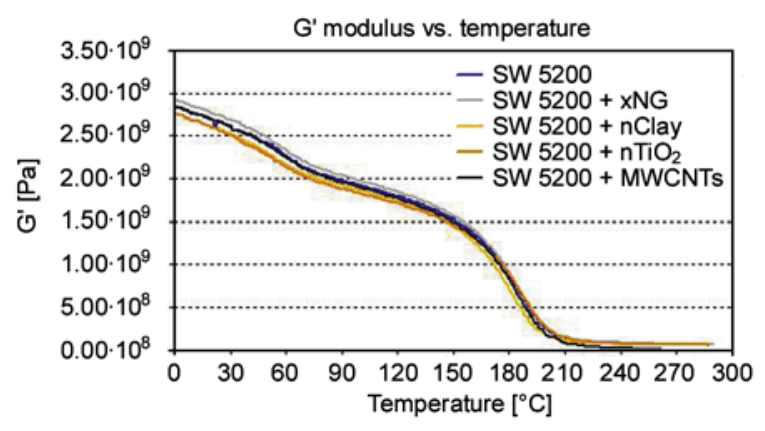

Figure 4. Prime modulus in torsion $\left(G^{\prime}\right)$, versus temperature for the epoxy gelcoats

fracture properties between the two inorganic fillers.

The effect of the rigid nanofillers on the glass transition temperature and on the storage and loss torsion modulus is shown in Table 2. The glass transition temperature, $T_{\mathrm{g}}$ and the storage modulus $G^{\prime}$ remained practically unaffected by the presence of the fillers. Nevertheless, $\tan \delta$ was decreased around $30 \%$ for all the nanofillers i.e. transforming the nanodoped epoxy gelcoats into a more 'elastic' material. Moreover, Figure 4 presents the $G^{\prime}$ modulus graph versus the tested temperature range where it can be seen that the effect of the nanofillers is not very significant.

In Figure 5. the DC volume conductivity measurements for the gelcoats are depicted. One may highlight that the inclusion of the conductive fillers i.e. CNTs and nanographite has further increased the

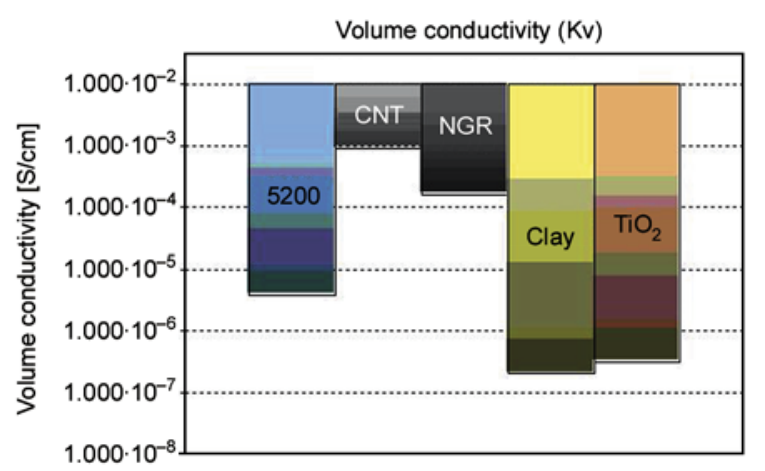

Figure 5. Volume conductivity properties of the nanomodified gelcoats versus the reference gelcoat

Table 2. DMA torsion properties of the nanomodified gelcoats versus the reference gelcoat

\begin{tabular}{|l|c|c|c|c|}
\hline \multicolumn{1}{|c|}{ Gelcoat reference } & $\left.\mathbf{T}_{\mathbf{g}}{ }^{\circ} \mathbf{C}\right]$ & $\mathbf{G}^{\prime}[\mathbf{P a}]$ & $\mathbf{G}^{\prime \prime}[\mathbf{P a}]$ & $\tan \boldsymbol{\delta}$ \\
\hline Rengel SW 5200 & 200.8 & $2.59 \cdot 10^{9}$ & $3.29 \cdot 10^{7}$ & 0.54979 \\
\hline Rengel SW 5200+ MWCNTs & 201.7 & $2.68 \cdot 10^{9}$ & $3.53 \cdot 10^{7}$ & 0.36472 \\
\hline Rengel SW 5200 + xnGraphite & 200.9 & $2.75 \cdot 10^{9}$ & $2.81 \cdot 10^{7}$ & 0.37041 \\
\hline Rengel SW 5200+ nClay & 197.8 & $2.58 \cdot 10^{9}$ & $3.37 \cdot 10^{7}$ & 0.38239 \\
\hline Rengel SW 5200 + nTiO $_{2}$ & 204.6 & $2.57 \cdot 10^{9}$ & $1.82 \cdot 10^{7}$ & 0.37492 \\
\hline
\end{tabular}


conductivity of the reference gelcoat between 2 and 1.5 orders of magnitude. Extensive researches on carbon nanotubes and their polymers have established that CNTs can be conductive, semi-conductive or even metallic depending on their structure and that only a small weigh fraction is needed to form a percolating network in a polymer or in a composite. The above is directly related to their graphene structure and their high aspect ratio and surface area which in turn is translated into electrical conductivity values of $10^{6}$ to $10^{7} \mathrm{~S} / \mathrm{m}[6,9-11]$. Additionally, the exfoliated nanographite with its basal plane to be inert $\left(s p^{2}+\pi\right)$ and identical to the wall of a carbon nanotube it has analogous electrical properties bringing thus similar improvement on the electrical properties $[5,8,16]$. The other two nanofillers actually reduced the electrical conductivity of the gelcoat about 2 orders of magnitude. This was expected since their ceramic nature involves high internal electrical resistance making thus, the gelcoat less more electrically resistant. At this point it must be noted that all the electrical measurement performed for DC frequency and that $\mathrm{AC}$ measurements will be performed as part of the continuation of this research, along with other tests, since the hybrid role of $\mathrm{TiO}_{2}$ has to be further investigated and evaluated [41]. Other tests that are currently being performed are abrasion resistance, water and salted water absorption and degradation. The effect of all the nanofillers on the thermal properties of the state of the art epoxy gelcoat is shown in Table 3. All the nanofillers by being thermally conductive improved the thermal conductivity of

Table 3. Thermal conductivity properties of the nanomodified gelcoats versus the reference gelcoat

\begin{tabular}{|l|c|c|}
\hline \multicolumn{1}{|c|}{ Gelcoat reference } & $\begin{array}{c}\text { Thermal conductivity } \\
{[\mathbf{W} /(\mathbf{m} \cdot \mathbf{K})]}\end{array}$ & st. dev \\
\hline Rengel SW 5200 & 0.54 & 0.0007 \\
\hline Rengel SW 5200+ MWCNTs & 0.60 & 0.0021 \\
\hline Rengel SW 5200+ xnGraphite & 0.63 & 0.0018 \\
\hline Rengel SW 5200+ nClay & 0.61 & 0.0014 \\
\hline Rengel SW 5200+ nTiO $_{2}$ & 0.58 & 0.0011 \\
\hline
\end{tabular}

the gelcoat in the range of 8 to $16 \%$. Several research studies have claimed that the presence of nanofillers like the CNTs, nanographite, nanoclay and titanium dioxide has been beneficial for the thermal stability of thermoplastics and thermosets. The reason for the abovementioned amelioration is not only the intrinsic properties of the fillers themselves i.e. CNTs have high melting point and thermal conductivity of at least $3000 \mathrm{~W} /(\mathrm{m} \cdot \mathrm{K})$, In systems like the ones under investigation, the thermal conductivity difference of the phases as well as the interfacial thermal resistance between them have a significant influence on the achieved thermal conductivity of the final nano-composite, besides the geometrical characteristics of the nano-fillers. The interfacial thermal resistance together with the resulting pathways define the phonon movement and as a result the thermal conductivity of the material. CNTs are able to create a critical path to diffuse thermal energy at this loading level. Based on an experimental study on thermally conductive composites filled with platelet-shaped boron nitride particles, it was suggested that fillers with platelet shape offer advantages over other spherical or cylindrical morphologies because they can overlap with a large contact area permitting much closer contact between adjacent platelets and reducing the thermal contact resistance [17, 34-39].

In addition, Table 4 depicts the data obtained for the coefficient of linear thermal expansion (CLTE) tests. The tests were performed at below and above the glass transition temperature, $T_{\mathrm{g}}$, of the reference gelcoat i.e. $200^{\circ} \mathrm{C}$. The effect at the CLTE value of all the nanofillers below $T_{\mathrm{g}}$ seems to be of no practical use. Nevertheless, the CLTE values for all the nano-enhanced epoxy gelcoats are reduced. In other words the nano-enhanced gelcoats will expand less than the reference material. Materials expand because an increase in temperature leads to greater thermal vibration of the atoms in a material, and hence to an increase in the average separation distance of adjacent atoms or polymer molecules in the

Table 4. Coefficient of linear thermal expansion values for above and below glass transiton temperature

\begin{tabular}{|c|c|c|c|c|}
\hline \multirow{2}{*}{ Gelcoat reference } & \multicolumn{2}{|c|}{ Below } & \multicolumn{2}{|c|}{ Above } \\
\hline & $\mathbf{T}_{\mathrm{g}}\left[\mathbf{m} /\left(\mathbf{m} \cdot{ }^{\circ} \mathbf{C}\right)\right]$ & st.dev & $\mathbf{T}_{\mathrm{g}}\left[\mathbf{m} /\left(\mathbf{m} \cdot{ }^{\circ} \mathbf{C}\right)\right]$ & st.dev \\
\hline Rengel 5200 & 49.98 & 0.20 & 128.61 & 1.10 \\
\hline GC MY510 + MWCNTs & 50.01 & 0.26 & 107.11 & 1.90 \\
\hline GC MY510 + xnGraphite & 51.11 & 0.59 & 120.77 & 1.47 \\
\hline GC MY510 + nClay & 49.60 & 0.60 & 112.00 & 0.91 \\
\hline $\mathrm{GC} \mathrm{MY} 510+\mathrm{nTiO}_{2}$ & 50.22 & 0.42 & 125.26 & 1.50 \\
\hline
\end{tabular}


case of thermosets. The size, the high surface area and the aspect ratio of the the fillers are responsible for the aforementioned improvement. The nanofillers occupy certain space among the polymer macromolecules making thus their vibration and their separation more difficult to occur.

Carbon based products ranging from coatings to wood and plastics form free radicals when exposed to ultra-violet (UV) radiations. These free radicals chemically react with oxygen to yield a photo oxidized product which modifies the product appearance and also its mechanical properties. The weatherometer (WOM) device uses a combination of carbon arc, UV radiation and water spray to simulate destructive weather conditions in an accelerated manner. Although precise equivalents are impossible to determine, a practical calculation is: 300 hours in the weatherometer equals one year real time. The data from WOM tests concern discolouration and colour fading of the samples and weight loss. In our study, the reference epoxy gelcoat was black and it remained black after the addition of the different nanofillers. As a consequence the discolouration/colour fading data were of no-practical value with the differences among the five types of specimens to be trivial. Therefore only the weight loss percentage data were of significance and are presented in the Figure 6 . The weight loss for the nano-filled epoxy gelcoats is less than the reference gelcoat, meaning that the reference samples were more prone to environmental degradation. In other words, in a real life situation the nanodoped gelcoats should have an extended life-time in comparison with the RenGel ${ }^{\mathrm{TM}} \mathrm{SW}$ 5200. Even though weatherometer results of nanodoped epoxies have not been previously published in the literature, there are however studies on the effect of nanofillers on the tribology, abrasion resistance and UV degradation properties of nano-enhanced resins. The presence of CNT can have a dramatic reinforcement effect on the nature of degradation by both high-energy radiations, where polymer-free radicals are mainly responsible for the proliferation of degradation. In addition, CNT networks can effectively disperse the radiation. The wear rate was reduced by a factor of 5.5 when the friction behaviour of MWCNTs epoxy polymer was studied [4243]. As for the ceramic nanofillers, nano titanium dioxide in rutile form proved to be very effective on

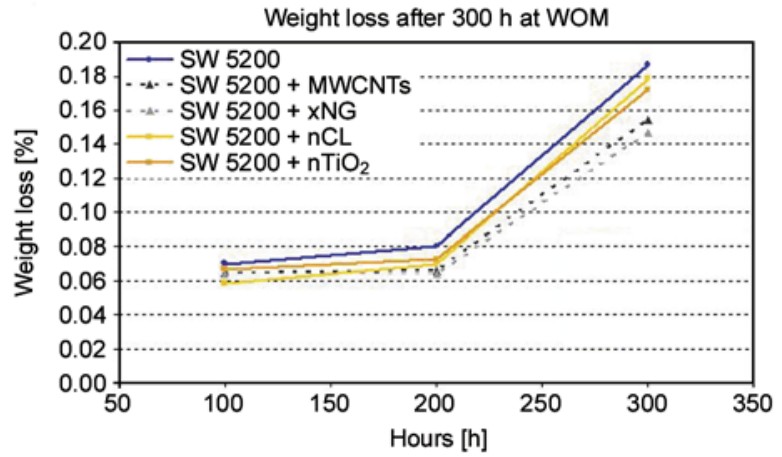

Figure 6. Weight loss data of weatherometer test of the nanomodified gelcoats versus the reference gelcoat

absorbing wavelengths below $350 \mathrm{~nm}$ and thus operating as a pacifier for isocyanate based acrylic coatings [44]. One may summarise that the use of nanofillers in the epoxy glecoat have proved their potential to enhance the resistance of the gelcoat in harsh environmental conditions.

\section{Conclusions}

In this work, the effect of the addition of four different commercially available nanofillers into a state of the art epoxy based gelcoat was studied. The nanofillers were introduced into the gelcoat in the form of a masterbatch which was prepared by using a high shear mixing device i.e. a 3-roll mill. The presence of the nanofillers brought a lot of improvements in the properties of the gelcoats. The aforementioned improvements include the tensile and fracture properties as well as, the electrical and thermal ones. The presence of the nanofillers also decreased the coefficient of linear thermal expnasion and made the nanodoped epoxy gelcoats more resistant to UV degradation. The addition of CNTs and the exfoliated nanographite lead to an allaround enhancement of properties, while the addition of nanoclay and nano-titanium dioxide was beneficial only for the tensile and thermal conductivity properties. However the inclusion of the nanofillers had no practical impact on glass transition temperature. One of the drawbacks of the introduction of the nanofillers into the resin was the increase of viscosity which can be an issue of processability of those materials when composite manufacturing is considered.

It must be highlighted that the aforesaid improvements in the case of the gelcoats are very important since the gelcoats are already heavily filled with various fillers (organic and inorganic) and they 
have been optimised for all-around good performance and properties. The extra properties gained by the addition of the nanofillers therefore are essential.

\section{Acknowledgements}

All the aforementioned work has been financially supported by the LAYSA EU-Transport Project with contract number: FP7-AAT-2007-RTD-1. The authors would like to thank Applied Mechanics Laboratory of University of Patras, Greece for their help with the thermal conductivity tests.

\section{References}

[1] Karapappas P., Vavouliotis A., Tsotra P., Paipetis A., Kostopoulos V.: Enhanced fracture properties of carbon reinforced composites by the addition of multiwall carbon nanotubes. Journal of Composite Materials, 43, 977-985 (2009).

DOI: $10.1177 / 0021998308097735$

[2] Kostopoulos V., Baltopoulos A., Karapappas P., Vavouliotis A., Paipetis A.: Impact and after-impact properties of carbon fibre reinforced composites enhanced with multi-wall carbon nanotubes. Composites Science and Technology, 70, 553-563 (2010). DOI: $10.1016 /$ j.compscitech.2009.11.023

[3] Wichmann M. H. G., Sumfleth J., Gojny F. H., Quaresimin M., Fiedler B., Schulte K.: Glass-fibre-reinforced composites with enhanced mechanical and electrical properties - Benefits and limitations of a nanoparticle modified matrix. Engineering Fracture Mechanics, 73, 2346-2359 (2006).

DOI: $10.1016 /$ j.engfracmech.2006.05.015

[4] Wichmann M. H. G., Schulte K., Wagner H. D.: On nanocomposite toughness. Composites Science and Technology, 68, 329-331 (2007).

DOI: $10.1016 /$ j.compscitech.2007.06.027

[5] Kalaitzidou K., Fukushima H., Drzal L. T.: A new compounding method for exfoliated graphite-polypropylene nanocomposites with enhanced flexural properties and lower percolation threshold. Composites Science and Technology, 67, 2045-2051 (2007). DOI: 10.1016/j.compscitech.2006.11.014

[6] Martin C. A., Sandler J. K. W., Shaffer M. S. P., Schwarz M-K., Bauhofer W., Schulte K., Windle A. H.: Formation of percolating networks in multi-wall carbon nanotube-epoxy composites. Composites Science and Technology, 64, 2309-2316 (2004).

DOI: $10.1016 /$ j.compscitech.2004.01.025

[7] Thostenson E. T., Chou T-W.: Processing structure multi functional property relationship in carbon nanotube/epoxy composites. Carbon, 44, 3022-3029 (2006). DOI: $10.1016 /$ j.carbon.2006.05.014
[8] Fukushima H., Drzal L. T., Rook B., Rich M. J.: Thermal conductivity of exfoliated graphite nanocomposites. Journal of Thermal Analysis and Calorimetry, 85, 235-238 (2006).

DOI: $10.1007 / \mathrm{s} 10973-005-7344-\mathrm{x}$

[9] Sandler J., Shaffer M. S. P., Prasse T., Bauhofer W., Schulte K., Windle A. H.: Development of a dispersion process for carbon nanotubes in an epoxy matrix and the resulting electrical properties. Polymer, 40, 5967-5971 (1999).

DOI: $10.1016 / \mathrm{S} 0032-3861(99) 00166-4$

[10] Sandler J. K. W., Kirk J. E., Kinloch I. A., Shaffer M. S. P., Windle A. H.: Ultra-low electrical percolation threshold in carbon-nanotube-epoxy composites. Polymer, 44, 5893-5899 (2003).

DOI: $10.1016 / \mathrm{S} 0032-3861(03) 00539-1$

[11] Dresselhaus M. S., Dresselhausand G., Avouris P. H.: Carbon nanotubes: Synthesis, structure, properties and applications. Springer, Berlin (2001).

[12] Fernberg, P., Nilsson G., Joffe R.: Piezoresistive performance of long-fiber composites with carbon nanotube doped matrix. Journal of Intelligent Material Systems and Structures, 20, 1017-1023 (2009). DOI: $10.1177 / 1045389$ X08097387

[13] Vavouliotis A., Karapappas P., Loutas T., Voyatzi T., Paipetis A., Kostopoulos V.: Multistage fatigue life monitoring on carbon fibre reinforced polymers enhanced with multiwall carbon nanotubes. Plastics, Rubber and Composites, 38, 124-130 (2009). DOI: $10.1179 / 174328909 X 387928$

[14] Kostopoulos V., Vavouliotis A., Karapappas P., Tsotra P., Paipetis A.: Damage monitoring of carbon fiber reinforced laminates using resistance measurements. Improving sensitivity using carbon nanotube doped epoxy matrix system. Journal of Intelligent Material Systems and Structures, 20, 1025-1034 (2009).

DOI: $10.1177 / 1045389$ X08099993

[15] Lachman N., Bartholome C., Miaudet P., Maugey M., Poulin P., Wagner H. D.: Raman response of carbon nanotube PVA fibers under strain. Journal of Physical Chemistry C, 113, 4751-4754 (2009).

DOI: $10.1021 / \mathrm{jp} 900355 \mathrm{k}$

[16] Kim S., Do I., Drzal L. T.: Thermal stability and dynamic mechanical behavior of exfoliated graphite nanoplatelets-LLDPE nanocomposites. Polymer Composites, 31, 755-761 (2009).

DOI: $10.1002 /$ pc. 20781

[17] Kim S., Drzal L. T.: High latent heat storage and high thermal conductive phase change materials using exfoliated graphite nanoplatelets. Solar Energy Materials and Solar Cells, 93, 136-142 (2009). DOI: 10.1016/j.solmat.2008.09.010 
[18] Allaoui A., El Bounia N.: How carbon nanotubes affect the cure kinetics and glass transition temperature of their epoxy composites? - A review. Express Polymer Letters, 3, 588-594 (2009).

DOI: $10.3144 /$ expresspolymlett.2009.73

[19] Castenada S., Parra O., Ramirez E., Sanchez S.: Performance of nanoclay in a flame-retardant jacket compound. Wire Journal International, 42, 70-79 (2009).

[20] Gilman J. W., Kashiwagi T., Lichtenhan J. D.: Nanocomposites: A revolutionary new flame retardant approach. SAMPE Journal, 33, 40-51 (1997).

[21] Chozhan C. K., Alagar M., Sharmila R. J., Gnanasundaram P.: Thermo mechanical behaviour of unsaturated polyester toughened epoxy-clay hybrid nanocomposites. Journal of Polymer Research, 14, 319327 (2007).

DOI: 10.1007/s10965-007-9114-X

[22] Al-Khanbashi A., El-Gamal M., Moet A.: Reduced shrinkage polyester-montmorillonite nanocomposite. Journal of Applied Science, 98, 767-773 (2005). DOI: 10.1002/app.22157

[23] Bhat G., Raghavendra R. H., Kamath M. G., Deshpande B.: Nanoclay reinforced fibers and nonwovens. Journal of Engineered Fibers and Fabrics, 3(3), 22-34 (2008).

[24] Boccaccini A. R., Karapappas P., Marijuan J. M., Kaya C.: $\mathrm{TiO}_{2}$ coatings on silicon carbide and carbon fibre substrates by electrophoretic deposition. Journal of Materials Science, 39, 851-859 (2004).

DOI: 10.1023/B:JMSC.0000012914.47793.3e

[25] Selvin T. P., Kuruvilla J., Sabu T.: Mechanical properties of titanium dioxide-filled polystyrene microcomposites. Materials Letters, 58, 281-289 (2004). DOI: $10.1016 / \mathrm{S} 0167-577 \mathrm{X}(03) 00470-1$

[26] Rohan L., Holmes J. A., Campbell P., Karatchevtseva I.: Pyrolysis behaviour of titanium dioxide-poly(vinyl pyrrolidone) composite materials. Polymer Degradation and Stability, 94, 1882-1889 (2009).

DOI: $10.1016 /$ j.polymdegradstab.2009.03.026

[27] Fiedler B., Gojny F. H., Wichmann M. H. G., Nolte M. C. M., Schulte K.: Fundamental aspects of nano-reinforced composites. Composites Science and Technology, 66, 3115-3125 (2006).

DOI: 10.1016/j.compscitech.2005.01.014

[28] Spitalsky Z., Tasis D., Papagelis K., Galiotis C.: Carbon nanotube-polymer composites: Chemistry, processing, mechanical and electrical properties. Progress in Polymer Science, 35, 357-401 (2010).

DOI: $10.1016 /$ j.progpolymsci.2009.09.003

[29] Tran C. D., Humphries W., Smith S. M., Huynh C., Lucas S.: Improving the tensile strength of carbon nanotube spun yarns using a modified spinning process. Carbon, 47, 2662-2670 (2009). DOI: $10.1016 /$ j.carbon.2009.05.020
[30] Seyhan T. A., Tanoğlu M., Schulte K.: Tensile mechanical behavior and fracture toughness of MWCNT and DWCNT modified vinyl-ester/polyester hybrid nanocomposites produced by 3-roll milling. Materials Science and Engineering: A, 523, 85-92 (2009). DOI: $10.1016 /$ j.msea.2009.05.035

[31] Gibson R. F.: A review of recent research on mechanics of multifunctional composite materials and structures. Composite Structures, 92, 2793-2810 (2010). DOI: $10.1016 /$ j.compstruct.2010.05.003

[32] Tsai J-L., Tu J-F.: Characterizing mechanical properties of graphite using molecular dynamics simulation. Materials and Design, 31, 194-199 (2010).

DOI: $10.1016 / \mathrm{j}$. matdes.2009.06.032

[33] Yasmin A., Daniel I. M.: Mechanical and thermal properties of graphite platelet/epoxy composites. Polymer, 45, 8211-8219 (2004).

DOI: $10.1016 /$ j.polymer.2004.09.054

[34] Miller S. G., Bauer J. L., Maryanski M. J., Heimann P. J., Barlow J. P., Gosau J-M., Allred R. E.: Characterization of epoxy functionalized graphite nanoparticles and the physical properties of epoxy matrix nanocomposites. Composites Science and Technology, 70, 11201125 (2010).

DOI: $10.1016 /$ j.compscitech.2010.02.023

[35] Kornmann X., Lindberg H., Berglund L. A.: Synthesis of epoxy-clay nanocomposites. Influence of the nature of the curing agent on structure. Polymer, 42, 44934499 (2001). DOI: $10.1016 / \mathrm{S} 0032-3861(00) 00801-6$

[36] Lan T., Kaviratna P. D., Pinnavaia T. J.: Epoxy selfpolymerization in smectite clays. Journal of Physics and Chemistry of Solids, 57, 1005-1010 (1996).

DOI: 10.1016/0022-3697(95)00388-6

[37] Auad M. L., Nutt S. R., Pettarin V., Frontini P. M.: Synthesis and properties of epoxy-phenolic clay nanocomposites. Express Polymer Letters, 1, 629-639 (2007).

DOI: $10.3144 /$ expresspolymlett.2007.86

[38] Becker O., Varley R., Simon G.: Morphology, thermal relaxations and mechanical properties of layered silicate nanocomposites based upon high-functionality epoxy resins. Polymer, 43, 4365-4373 (2002).

DOI: $10.1016 / \mathrm{S} 0032-3861(02) 00269-0$

[39] Ratna D., Manoj N. R., Varley R., Singh Raman R. K., Simon G. P.: Clay-reinforced epoxy nanocomposites. Polymer International, 52, 1403-1407 (2003). DOI: $10.1002 /$ pi.1166

[40] Kostopoulos V., Karapappas P., Loutas T., Vavouliotis A., Paipetis A., Tsotra P.: Interlaminar fracture toughness of carbon fibre-reinforced polymer laminates with nano- and micro-fillers. Strain, in press (2011). DOI: $\underline{10.1111 / \mathrm{j} .1475-1305.2008 .00612 . \mathrm{x}}$ 
[41] Kontos G. A., Soulintzis A. L., Karahaliou P. K., Psarras G. C., Georga S. N., Krontiras C. A., Pisanias M. N.: Electrical relaxation dynamics in $\mathrm{TiO}_{2}-$ polymer matrix composites. Express Polymer Letters, 1, 781789 (2007).

DOI: 10.3144/expresspolymlett.2007.108

[42] Najafi E., Shin K.: Radiation resistant polymer-carbon nanotube nanocomposite thin films. Colloids and Surfaces A: Physicochemical and Engineering Aspects, 257, 333-337 (2005).

DOI: $10.1016 /$ j.colsurfa.2004.10.076
[43] Zhang L. C., Zarudi I., Xiao K. Q.: Novel behaviour of friction and wear of epoxy composites reinforced by carbon nanotubes. Wear, 261, 806-811 (2006). DOI: $10.1016 /$ j.wear.2006.01.033

[44] Allen N. S., Edge M., Ortega A., Liauw C. M., Stratton J., McIntyre R. B.: Behaviour of nanoparticle (ultrafine) titanium dioxide pigments and stabilisers on the photooxidative stability of water based acrylic and isocyanate based acrylic coatings. Polymer Degradation and Stability, 78, 467-478 (2002).

DOI: $10.1016 / \mathrm{S} 0141-3910(02) 00189-1$ 